\title{
Till We Win: India's Fight Against the COVID-19 Pandemic: Chandrakant Lahariya, Gagandeep Kang, Randeep Guleria
}

\author{
Published by Penguin Books; Gurgaon, India; 2020; ISBN: 978-0-143-45180-8
}

\author{
Rakesh Lodha ${ }^{1}$ \\ Received: 26 March 2021 / Accepted: 26 March 2021 / Published online: 15 April 2021 \\ (C) Dr. K C Chaudhuri Foundation 2021
}

'Till We Win' is an excellent narrative and analysis of India's response to the COVID-19 pandemic by authors who are experts in their respective fields.

In eleven chapters under four sections, the book covers basics of virus, pandemics, and the issues specific to the COVID-19 pandemic; chronicle of the country's response to the pandemic so far; various aspects of management strategies of COVID-19 and potential vaccines; and the public health response to the pandemic, making the most of the current crisis to strengthen the health systems in the country, and the paradigm of the 'new normal'.

The first section is a very interesting description of viruses, various ecosystems, and why pandemics occur, in lucid language. The style of writing makes difficult concepts easy to understand, which will be useful for lay people and policy makers, etc. The description of the spectrum of manifestations of COVID-19 is comprehensive.

The second section chronicles the country's response to the pandemic beginning with the detection of the first case in the country, regional and country level responses. The section describes various aspects of control of pandemic, the public health response including the lockdown, scaling up the diagnostic services and organization of care facilities including home isolation. The challenges of the 'unlock' are discussed in detail as are the responses to these challenges. The section also covers the dichotomy in the society's action and attitude towards the front-line workers with incidents of maltreatment of the latter. It fittingly highlights the contributions and sacrifices of the frontline workers, beyond the call of their duties.

Rakesh Lodha

rlodha1661@gmail.com

1 Department of Pediatrics, All India Institute of Medical Sciences, New Delhi 110029, India
Section three deals with the global attempts at finding cures to the virus and presents the current state of evidence for the same. It describes the various approaches being used for vaccine development and for the benefit of lay public, describes basics of the various processes including clinical trials. In a question-and-answer format, the authors address various queries that we face.

The last section delves into the need and urgency for strengthening of the country's public health system. It clearly highlights the importance of a 'knowledge- and evidencebased response.' Given the poor state of the health systems, the authors advocate for using the current crisis as an opportunity to strengthen and transform the systems, increase the budgetary allocations for health, and to strive for Universal Health Coverage. It also highlights various innovations and solutions already implemented to provide the continuum of healthcare. The last chapter of the book warns us about the need for adhering to the basics of disease prevention as COVID-19 is likely to stay with us.

The format of the book, apart from well-written narratives, includes information in boxes for an impact and also summarizes the lessons learnt in "What did everyone learn during this period?". The book will serve as an excellent resource for healthcare professionals, policy makers, and lay public, alike.

Publisher's Note Springer Nature remains neutral with regard to jurisdictional claims in published maps and institutional affiliations. 